\title{
Identification and characterization of an oocyte factor required for sperm decondensation in pig
}

\author{
Jingyu Li*, Yanjun Huan, Bingteng Xie, Jiaqiang Wang, Yanhua Zhao, Mingxia Jiao, \\ Tianqing Huang, Qingran Kong and Zhonghua Liu
}

Laboratory of Embryo Biotechnology, College of Life Science, Northeast Agricultural University, Harbin, Heilongjiang Province 150030, China and ${ }^{1}$ Shandong Academy of Agricultural Sciences, Dairy Cattle Research Center, Jinan, Shandong Province 250100, China

Correspondence should be addressed to Z Liu; Email: liu086@126.com or to Q Kong; Email: kqr086@yahoo.com

*(J Li and Y Huan contributed equally to this work)

\begin{abstract}
Mammalian oocytes possess factors to support fertilization and embryonic development, but knowledge on these oocyte-specific factors is limited. In the current study, we demonstrated that porcine oocytes with the first polar body collected at $33 \mathrm{~h}$ of in vitro maturation sustain IVF with higher sperm decondensation and pronuclear formation rates and support in vitro development with higher cleavage and blastocyst rates, compared with those collected at $42 \mathrm{~h}(\boldsymbol{P}<0.05)$. Proteomic analysis performed to clarify the mechanisms underlying the differences in developmental competence between oocytes collected at 33 and $42 \mathrm{~h}$ led to the identification of 18 differentially expressed proteins, among which protein disulfide isomerase associated 3 (PDIA3) was selected for further study. Inhibition of maternal PDIA3 via antibody injection disrupted sperm decondensation; conversely, overexpression of PDIA3 in oocytes improved sperm decondensation. In addition, sperm decondensation failure in PDIA3 antibody-injected oocytes was rescued by dithiothreitol, a commonly used disulfide bond reducer. Our results collectively report that maternal PDIA3 plays a crucial role in sperm decondensation by reducing protamine disulfide bonds in porcine oocytes, supporting its utility as a potential tool for oocyte selection in assisted reproduction techniques.

Reproduction (2014) 148 367-375
\end{abstract}

\section{Introduction}

Assisted reproductive technology (ART) has attracted significant public interest since the birth of the first IVF baby. ART allows manipulation of the fertilization process to bypass a number of reproductive diseases (Katz et al. 2002). Despite widespread application of IVF and ICSI in ART, current pregnancy and live birth success rates remain unsatisfactory (Mahutte \& Arici 2003, Society for Assisted Reproductive Technology; American Society for Reproductive Medicine 2004), and only $32 \%$ of IVF cycles result in pregnancy (de Mouzon et al. 2010). The major reason for this limited success is low oocyte developmental competence (Gosden 2002, Sun \& Nagai 2003, Krisher 2004, Swain \& Pool 2008), which refers to the molecular state that allows a mature oocyte to support fertilization, preimplantation embryo development, and implantation. Therefore, elucidation of the components and mechanisms involved in oocyte developmental competence should provide crucial information to assist in the fields of reproductive and developmental biology.
Maternal proteins and transcripts are essential for acquisition and maintenance of oocyte developmental competence (Newport \& Kirschner 1982, Morisato \& Anderson 1995, Brevini et al. 2007a), and play critical roles in reproductive processes, such as oocyte maturation, fertilization, zygotic gene activation, and embryonic development. For instance, the absence of MATER, one of the maternal effector proteins in mice, results in embryo arrest at the two-cell stage (Tong et al. 2000). Other factors identified in individual studies include NPM2, DPPA3, PADI6, TLE6, and FLOPED (Burns et al. 2003, Payer et al. 2003, Esposito et al. 2007, Li et al. 2008). However, several unknown core factors remain to be determined. Transcriptomic and proteomic are currently underway to gain further insights into the significance of maternal factors, and DNA microarray technology has provided valuable information on maternal factors at the transcriptional level (Hamatani et al. 2004, Wang et al. 2004, Zeng et al. 2004). As oocyte transcription decreases rapidly during maturation (Sternlicht \& Schultz 1981), proteomic technologies 
are necessary to elucidate the nature of developmental competence in oocytes.

Several investigators have explored the role of maternal proteins using proteomics, including from bovine, porcine, and mouse oocyte proteomes (Calvert et al. 2003, Ellederova et al. 2004, Memili et al. 2007, Susor et al. 2007, Vitale et al. 2007, Zhang et al. 2009, Wang et al. 2010). Wang et al. (2010) successfully identified 2781 proteins in the germinal vesicle (GV) of mouse oocytes, 2973 proteins in meta-phase II (MII) oocytes, and 2082 proteins in zygote. The Zhang group identified 625 proteins from 2700 mature mouse oocytes lacking zona pellucidae, providing the first large-scale catalog of mature mouse oocyte proteins. However, considering the intense synthesis and degradation of maternal proteins during maturation, comparative analysis of key maternal proteins of oocytes at two approximate stages of maturation with different developmental competence may be more effective in identifying factors crucial for fertilization and development than the commonly used method of comparing proteome signatures between GV and MII oocytes. Pigs represent an ideal model for reproduction and biomedical applications owing to their morphological and functional similarities with humans (Brevini et al. 2007b, Hall 2008).

In this study, mature porcine oocytes collected at $33 \mathrm{~h}$ (33O) of in vitro maturation (IVM) displayed a higher competence in sustaining IVF embryo development, compared with those collected at $42 \mathrm{~h}(42 \mathrm{O})$. Comparison of the proteome signatures of $33 \mathrm{O}$ and $42 \mathrm{O}$ via mass spectrometry (MS) resulted in the successful identification of 18 differentially expressed proteins. Further examination of the functions of the proteins identified in IVF and ICSI embryos revealed that protein disulfide isomerase associated 3 (PDIA3) is required for successful porcine sperm decondensation. Our results collectively support the potential of PDIA3 as a novel marker for the selection of oocytes to produce embryos with higher fertilization and developmental competence.

\section{Materials and methods}

\section{Porcine oocyte IVM}

Porcine ovaries were collected from a local slaughterhouse and maintained in saline at $32-37^{\circ} \mathrm{C}$. The antral follicles $(3-5 \mathrm{~mm}$ diameter) were aspirated with an 18-gauge needle. The aspirated oocytes with evenly granulated cytoplasm and at least three uniform layers of compact cumulus cells were selected and cultured in four-well plates (Nunc, Naperville, IL, USA) containing $500 \mu \mathrm{l} \mathrm{TCM199} \mathrm{maturation} \mathrm{medium} \mathrm{(Gibco)}$ plus $0.05 \mu \mathrm{g} / \mathrm{ml}$ epidermal growth factor, $0.5 \mu \mathrm{g} / \mathrm{ml}$ luteinizing hormone, and follicle-stimulating hormone at $39{ }^{\circ} \mathrm{C}$ in $5 \% \mathrm{CO}_{2}$ in air. Porcine oocytes with the first polar body were collected at 33 and $42 \mathrm{~h}$ for further experiments.

\section{Oocyte collection and proteomic analysis}

Zona pellucida with more than 10000 oocytes at 33 and $42 \mathrm{~h}$ of IVM were removed and total proteins were extracted using ultrasonic wave and lysis buffer (7 M urea, $2 \mathrm{M}$ thiourea, 4\% (w/v) CHAPS, $65 \mathrm{mM}$ dithiothreitol (DTT), 2\% (v/v), and $1 \%(\mathrm{v} / \mathrm{v})$ protease inhibitor cocktail). Protein concentrations were determined using the Bradford method, and the $\mathrm{pH}$ was adjusted to 8.5 with $50 \mathrm{mM} \mathrm{NaOH}$. In a two-dimensional difference gel electrophoresis (2D DIGE), proteins from oocytes at 33 and $42 \mathrm{~h}$ of IVM were equally pooled together and labeled with Cy2 as the internal standard, while the two individual samples were labeled separately with Cy3 or Cy5. The labeled samples were mixed in rehydration buffer before loading onto 24-cm Immobiline dry strips (IPG strips) of pH3-10 (Bio-Rad) and run on a single 2D gel. Subsequently, the gels were scanned using the Typhoon 9410 scanner at the excitation/emission wavelengths of $488 / 520 \mathrm{~nm}$ for Cy2, 532/580 nm for Cy3, and 633/670 nm for Cy5. Image analysis was performed with Decyder Software suite 5.02 (GE Healthcare, Uppsala, Sweden), which allows comparison of the different combinations corresponding to the experimental conditions. An independent $t$-test was used to determine the significance between experimental groups. $P$ values $<0.05$ and fold changes $>1.5$ were considered statistically significant.

For identification of protein, the spots of interest were excised from the gels, washed with $25 \mathrm{mM} \mathrm{NH}_{4} \mathrm{HCO}_{3}$ and $50 \% \mathrm{ACN}$ solution, dehydrated with $100 \%$ ACN sequentially, and dried via centrifugal lyophilization. The gels were digested with 15-20 $\mu \mathrm{l}$ of $0.01 \mu \mathrm{g} / \mu \mathrm{l}$ trypsin (Promega) in $25 \mathrm{mM}$ ammonium bicarbonate for $15 \mathrm{~h}$ at $37^{\circ} \mathrm{C}$. The supernatants fractions were collected and tryptic peptides sequentially extracted from the gel with $5 \%$ trifluoroacetic acid (TFA) at $40{ }^{\circ} \mathrm{C}$ for $1 \mathrm{~h}$ and $2.5 \%$ TFA, $50 \%$ $\mathrm{ACN}$ at $30{ }^{\circ} \mathrm{C}$ for $1 \mathrm{~h}$. The extracts were pooled and completely dried via centrifugal lyophilization. The digested peptides mixed with matrix $(50 \%$ acetonitrile, $0.1 \%$ TFA-containing $3 \mathrm{mg} / \mathrm{ml}$ $\alpha$-cyano-4-hydroxy cinnamic acid matrix) were spotted on the target plate. The samples were analyzed using MALDI TOF/TOF MS (4800 Proteomics Analyzer, Applied Biosystems) in the positive reflectron mode at fixed laser fluency with low-mass gate and delayed extraction. The parent mass peaks with a mass range of 700-4000 Da were set for tandem TOF/TOF analysis. Database searches were performed using Mascot version 2.2 (MatrixScience, London, UK) via GPS Explorer Software (ABI, Zurich, Switzerland) version 3.6 combining MS and MS/MS interrogations on the $\mathrm{NCBI}$ pig protein database used in

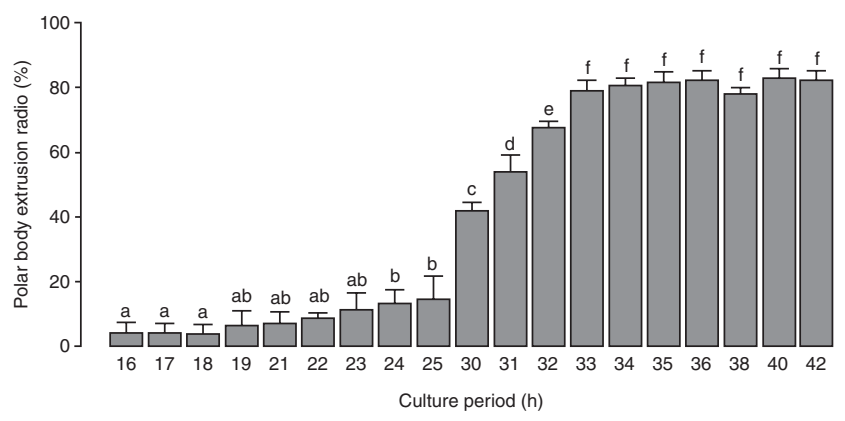

Figure 1 Percentage of polar body extrusion oocytes during IVM. Results are presented as means \pm S.E.M. Different letters represent significant differences $(P<0.05)$. 
Table 1 The effect of $33 \mathrm{O}$ and $42 \mathrm{O}$ on fertilization.

\begin{tabular}{lccc}
\hline $\begin{array}{l}\text { Culture } \\
\text { period }(h)\end{array}$ & Replicates & $\begin{array}{c}\text { No. of } \\
\text { oocytes }\end{array}$ & $\begin{array}{c}\text { No. of fertilization } \\
(\% \pm \text { S.E.M. })\end{array}$ \\
\hline 33 & 6 & 395 & $339(85.85 \pm 3.28)^{*}$ \\
42 & 6 & 363 & $277(76.61 \pm 3.86)^{+}$ \\
\hline
\end{tabular}

Values in the same column with different superscript symbols differ significantly $(P<0.05)$.

January 2012. For the search parameters, modifications were set as carbamido-methylation, oxidation, and a permitted maximum of one missed trypsin cleavage. Tolerance of precursor and fragment ions were both set to 0.2 Da. In cases where more than one protein was identified in one spot, the single protein member with the highest score (top rank) was singled out. All proteins with a statistically significant score (based on combined mass and mass/mass spectra) and best ion score (based on mass/mass spectra) were identified as potential factors.

\section{PDIA3 mRNA in vitro transcription}

The porcine PDIA3 sequence (NM_001195112) was obtained from the GenBank Database (http://www.ncbi.nlm.nih.gov/) and cloned using RT-PCR. RNA synthesis and poly(A) tailing were carried out with a MEGAscript T7 Kit (Ambion, Carlsbad, CA, USA) according to the manufacturer's instructions.

\section{DTT treatment}

Freshly ejaculated sperm sample were collected from fertile boars, and resuspended and washed three times in Dulbecco's PBS (DPBS) supplemented with $0.1 \%(\mathrm{w} / \mathrm{v})$ BSA via centrifugation at $1500 \mathrm{~g}$ for $4 \mathrm{~min}$. Before DTT treatment, the sperms were washed in DPBS with the nonionic detergent Triton X-100 $(\mathrm{TX}-100)$ at $1 \%(\mathrm{v} / \mathrm{v})$ at room temperature for removal of membrane to facilitate direct exposure of sperm nucleus to DTT. The sperms were incubated at $37^{\circ} \mathrm{C}$ in DPBS supplemented with $5 \mathrm{mM}$ DTT (Wako Pure Chemical Industries, Osaka, Japan). After incubation for $1 \mathrm{~min}$, the sperms were washed in DBPS and used for ICSI.

\section{Sperm decondensation assay}

The sperm were classified as condensed and decondensed according to refringency and size of the nucleus. The condensed sperm were bright, especially at the edge, and had no or slightly enlarged nucleus, while decondensed sperm displayed a large nucleus and loss of original morphology, and were gray and almost translucent (Supplementary Fig. 2, see section on supplementary data given at the end of this article).

\section{Embryo manipulation}

Before IVF and ICSI, $10 \mathrm{pl}$ PDIA3 antibody (anti-PDIA3; Ab13507, Abcam, Cambridge, USA) or $100 \mathrm{ng} / \mu \mathrm{l}$ mRNA solution were injected into the mature oocytes. After injection, the oocytes were incubated for at least $2 \mathrm{~h}$ before manipulation, to allow binding of endogenous PDIA3 to the antibody and translation of PDIA3 mRNA. The procedure for porcine
IVF was the same as that described previously (He et al. 2013). Briefly, freshly ejaculated sperm-rich fractions were collected from fertile boars. Following short incubation at $39^{\circ} \mathrm{C}$, the semen was resuspended and washed three times in DPBS supplemented with $0.1 \%(\mathrm{w} / \mathrm{v})$ BSA via centrifugation at $1500 \mathrm{~g}$ for $4 \mathrm{~min}$. Spermatozoa concentrations were measured using a hemocytometer, and the proportion of motile sperm was determined. Next, spermatozoa were diluted with modified Tris-buffered medium (mTBM) to an optimal concentration. The cumulus-free oocytes were washed three times in mTBM. Approximately, 30 oocytes were inseminated in $50 \mathrm{ml} \mathrm{mTBM}$ at a final sperm concentration of $3 \times 10^{5} / \mathrm{ml}$ for $5 \mathrm{~h}$. The embryos were cultured in porcine zygote medium-3 at $39{ }^{\circ} \mathrm{C}$ in $5 \% \mathrm{CO}_{2}$ in air. Cleavage and blastocyst rates were assessed at 48 and $156 \mathrm{~h}$ after activation, and the number of blastocyst was examined via nuclear staining with $5 \mu \mathrm{g} / \mathrm{ml}$ Hoechst 33342.

ICSI was performed by using an inverted microscope (Olympus IX71, Olympus Optical Co. Ltd.) with a piezoactuated micromanipulator (PMAS-CT150; Prime Tech Ltd, Tsuchiura, Japan). A $100 \mathrm{ml}$ drop of HEPES-M199 containing $0.5 \%(\mathrm{v} / \mathrm{v}) \mathrm{FBS}$ and $20 \mathrm{ml}$ drop of $4 \%(\mathrm{w} / \mathrm{v})$ polyvinylpyrrolidone (PVP, MW 360 000; Sigma) were placed in a 35-mm dish and covered with mineral oil. Next, 20-30 oocytes were placed in the $100 \mathrm{ml}$ drop and the sperm suspension was transferred to the PVP drop. The oocyte was positioned with a holding pipette so that the first polar body was at the 6 or 12 o'clock position. A single sperm was injected into the cytoplasm with a micropipette. Activation of ICSI zygotes was induced with 2DC pulses of $1.2 \mathrm{kV} / \mathrm{cm}$ for $30 \mathrm{~ms}$ on a BTX Elector-Cell Manipulator 2001 (BTX, San Diego, CA, USA). After $2 \mathrm{~h}$ of IVF and $3 \mathrm{~h}$ of ICSI, the zygotes were stained with $5 \mu \mathrm{g} / \mathrm{ml}$ Hoechst 33342 to examine the morphology of the sperm nucleus.

\section{Western blotting analysis}

The oocytes depleted of the zona pellucida were removed from storage at $-80{ }^{\circ} \mathrm{C}$ and transferred to $10 \mu \mathrm{l}$ cold $40 \mathrm{mM}$ sodium phosphate, containing $50 \mathrm{mM} \mathrm{NaCl}, 50 \mu \mathrm{M}$ sodium orthovanadate, $10 \mathrm{mM}$ sodium fluoride, $20 \mu \mathrm{M}$ MG-132, $2 \mu \mathrm{M}$ matrix metalloprotease inhibitor III (444264, Calbiochem, San Diego, CA, USA), and $1 \%$ protease inhibitor cocktail III (539134, Calbiochem, San Diego, CA, USA). Homogenization was carried out at $4{ }^{\circ} \mathrm{C}$ using a Tekmar homogenizer at three $15 \mathrm{~s}$ bursts with $1 \mathrm{~min}$ cooling in between. The homogenates were centrifuged at $4{ }^{\circ} \mathrm{C}$ for $1 \mathrm{~h}$ at $100000 \mathrm{~g}$. The supernatants were referred to as 'soluble' fractions. The pellets were suspended in $0.2-0.25 \mathrm{ml}$ complete buffer containing 1\% ASB-14 and mixed every $15 \mathrm{~min}$ for $2 \mathrm{~h}$ with Radnoti glass pestles

Table 2 The rate of embryos derived from $33 \mathrm{O}$ and $42 \mathrm{O}$ with decondensed sperms after $2 \mathrm{~h}$ of IVF.

\begin{tabular}{lccc}
\hline $\begin{array}{l}\text { Culture } \\
\text { period }(\mathrm{h})\end{array}$ & Replicates & $\begin{array}{c}\text { No. of oocytes } \\
\text { fertilized }\end{array}$ & $\begin{array}{c}\text { No. of zygotes with } \\
\text { decondensed sperms } \\
(\% \pm \text { S.E.M. })\end{array}$ \\
33 & 3 & 57 & $48(84.21 \pm 4.15)^{*}$ \\
42 & 3 & 42 & $29(66.67 \pm 6.51)^{\dagger}$ \\
\hline
\end{tabular}

Values in the same column with different superscript symbols differ significantly $(P<0.05)$. 
Table 3 The pronuclear rates of embryos derived from $33 \mathrm{O}$ and $42 \mathrm{O}$ after $12 \mathrm{~h}$ of IVF.

\begin{tabular}{lccc}
\hline $\begin{array}{l}\text { Culture } \\
\text { period }(h)\end{array}$ & Replicates & $\begin{array}{c}\text { No. of oocytes } \\
\text { fertilized }\end{array}$ & $\begin{array}{c}\text { No. of pronucleus } \\
(\% \pm \text { s.E.M. })\end{array}$ \\
\hline 33 & 3 & 65 & $62(95.20 \pm 1.07)^{*}$ \\
42 & 3 & 41 & $33(80.63 \pm 2.44)^{+}$ \\
\hline
\end{tabular}

Values in the same column with different superscript symbols differ significantly $(P<0.05)$.

(Unitek, Monrovia, CA, USA). After centrifugation at $4{ }^{\circ} \mathrm{C}$ for $1 \mathrm{~h}$ at $100000 \mathrm{~g}$, the supernatant fractions (referred to as 'membrane extracts') were removed and the pellets discarded. About 50 oocytes or embryos of each soluble and membrane extract for each gene test were separated via lithium dodecyl sulfate polyacrylamide electrophoresis on $4-12 \%$ Bis-Tris NuPAGE gels and transferred to PVDF membranes (Invitrogen). Nonspecific binding was blocked by overnight incubation in $1 \%$ casein in PBS at room temperature. The blots were probed for 2-4 $\mathrm{h}$ at room temperature with antibodies against PDIA3 (anti-PDIA3; ab13507, Abcam). Histone H2B (anti-H2B; ab40975, Abcam) served as the loading control. After $2 \mathrm{~h}$ incubation at room temperature with secondary antibodies, protein bands were detected via ECL using the RPN2108 Kit (Amersham) and Kodak BioMax Light film (Eastman Kodak Co.).

\section{Immunofluorescence analysis}

The oocytes and zygotes without zona pellucida were washed twice in PBS, fixed in freshly prepared $4 \%$ paraformaldehyde in PBS, permeabilized in 1\% TX-100 in PBS, and incubated in a blocking solution (1\% BSA in PBS) for $1 \mathrm{~h}$. For immunolabeling, the embryos were incubated overnight at $4{ }^{\circ} \mathrm{C}$ with antiPDIA3 subunit (anti-PDIA3; ab13507, Abcam), washed three times, and incubated for $1 \mathrm{~h}$ with secondary FITC-labeled goat anti-rabbit IgG (Invitrogen, A11008) diluted 1:1000 with a blocking solution. Immunofluorescence analysis of injected oocytes without the PDIA3 primary antibody (only secondary antibody was used) was carried out to determine PDIA3 antibody injection. The samples were washed and counterstained with $5 \mu \mathrm{g} / \mathrm{ml}$ Hoechst 33342. Fluorescence was detected and imaged using a Nikon fluorescence microscope.

\section{Statistical analyses}

Statistical analyses were performed using SPSS 13.0 for MicroSoft Windows. Data are presented as means \pm s.D. Oneway ANOVA was used to assess differences between two groups. The Duncan method was employed for pairwise comparisons, followed by Bonferroni's correction. Data were considered statistically significant at $P<0.05$ (two-tailed).
Decondensation rates of DTT-treated and untreated sperm in ICSI were analyzed using Duncan's multiple-range test.

\section{Results}

\section{Different developmental competence of $33 \mathrm{O}$ and $42 \mathrm{O}$ in IVF}

Time-dependent characteristics of porcine oocytes were examined during IVM through assessment of the first polar body extrusion rate from 16 to $42 \mathrm{~h}$. Our data showed that first polar body extrusion rate was significantly higher at $33 \mathrm{~h}$ of IVM (76.72\%) compared with all previous time points, but similar to those at all subsequent time points until $42 \mathrm{~h}(81.80 \%)$ (Fig. 1). Therefore, we employed $33 \mathrm{O}$ and $42 \mathrm{O}$ for porcine IVF. Notably, the rates of fertilization, sperm decondensation, pronuclear formation, cleavage, and blastocyst formation of IVF embryos derived from 330 were significantly higher than those from $42 \mathrm{O}$ (Tables 1, 2, 3 and 4). These results suggest that 330 has greater advantages in producing IVF embryos and supporting embryo development than $42 \mathrm{O}$.

\section{Proteomic analysis of 330 and $42 O$}

In view of the significantly different fertilization and developmental competence rates of 330 and $42 \mathrm{O}$, these two oocyte stages provide a good model for identifying novel maternal factors. Accordingly, the proteome signatures of 330 and 420 were compared, with a view to determine the core factors responsible for porcine IVF embryo development. After oocyte collection and treatment, total proteins were separated with 2D DIGE (Fig. 2A). Analysis of gel images revealed 994 paired protein spots. Application of the independent $t$-test to calculate differentially expressed proteins disclosed 21 protein spots with fold changes $>1.5$ $(P<0.05$; Fig. 2B). Overall, 18 proteins were identified via MS. Based on MALDI-TOF/MS analysis, seven proteins were upregulated and 11 were downregulated in 330, compared with $42 \mathrm{O}$ (Supplementary Table 1, see section on supplementary data given at the end of this article). Differentially expressed proteins were classified into groups based on molecular function, biological process, and cellular component by Gene Ontology analysis (Supplementary Fig. 1, see section on supplementary data given at the end of this article). Among these proteins, HSP90B1, HSPA5, and HSP90AB1 function as chaperones and their abundance

Table 4 In vitro development of IVF embryos derived from $33 \mathrm{O}$ and $42 \mathrm{O}$.

\begin{tabular}{lcccc}
\hline $\begin{array}{l}\text { Culture } \\
\text { period }(h)\end{array}$ & Replicates & $\begin{array}{c}\text { No. of embryos } \\
\text { cultured }\end{array}$ & $\begin{array}{c}\text { No. of embryos cleaved } \\
(\% \pm \text { S.E.M. })\end{array}$ & $\begin{array}{c}\text { No. of blastocysts } \\
(\% \pm \text { S.E.M. })\end{array}$ \\
\hline 33 & 5 & 314 & $247(78.36 \pm 1.19)^{*}$ & $\begin{array}{c}\text { Total cell no. of blastocysts } \\
(\mathrm{mean} \pm \text { S.E.M. })\end{array}$ \\
42 & 5 & 309 & $210(67.22 \pm 2.53)^{+}$ & $\begin{array}{c}106(33.79 \pm 1.89)^{*} \\
60(19.73 \pm 1.2)^{+}\end{array}$ \\
\hline
\end{tabular}

Values in the same column with different superscript symbols differ significantly $(P<0.05)$. 

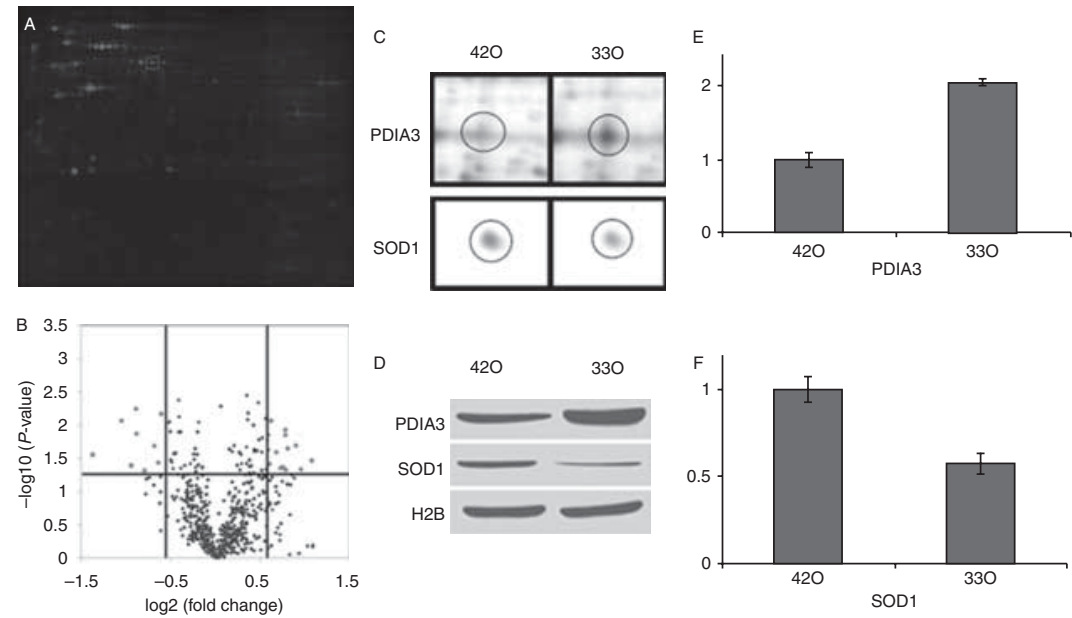

Figure 2 Silver staining analysis of 2DE DIGE map and validation by western blotting assay. (A) Total proteins separated using 2D DIGE. The gel marked by the gray square box signifies the PDIA3 protein spot. (B) All protein spots from 2D DIGE analysis. The horizontal axis represents the average log2 (ratio) of proteins $(42 \mathrm{O} / 33 \mathrm{O})$ whereas the vertical axis represents the $-\log 10$ ( $P$ value), $P$ value from $t$-test. Bigger plots represent protein spots that are significantly changed ( $>1.5$ fold and $P<0.05$ ). (C) PDIA3 and SOD1 spots in $33 \mathrm{O}$ and $42 \mathrm{O}$ from the 2DE DIGE map. (D) Validation of differentially expressed proteins by western blotting assay.

( $E$ and $F$ ) The differences in abundances of PDIA3 and SOD1 between $33 \mathrm{O}$ and $42 \mathrm{O}$ were significant at the level $P<0.05$ for two independent gels for each stage of oocyte. changes are involved in oocyte maturation (Ellederova et al. 2004, Wang et al. 2010). One unique protein spot expressed at high levels in $33 \mathrm{O}$ and low levels in $42 \mathrm{O}$ (Fig. 2A (gray box), C and E) was matched to PDIA3 with MALDI-TOF/MS analysis and database searches. To verify the results of our 2DE DIGE gel analysis, we selected two proteins for western blotting analysis (Fig. 2C, D, E and F). Earlier studies have shown that PDIA3 catalyzes disulfide bond reduction, the first step of sperm decondensation, similar to PDIs (Zapun et al. 1998, Frickel et al. 2004). Therefore, considering the differential expression patterns of PDIA3 in $42 \mathrm{O}$ and $33 \mathrm{O}$, we hypothesize that low expression of PIDA3 in $42 \mathrm{O}$ is insufficient to reduce sperm nuclear disulfide bonds, resulting in minimal sperm decondensation.

\section{Effect of PDIA3 on sperm decondensation in IVF embryos}

In general, porcine oocytes with the first polar body at $42 \mathrm{~h}$ of IVM are used for IVF and ICSI studies (Funahashi \& Day 1997). Exploration of the function of maternal PDIA3 in 420 may therefore be more relevant. To examine the role of PDIA3 in sperm nucleus decondensation, its expression was inhibited or enhanced by injecting anti-PDIA3 antibody or PDIA3 $\mathrm{mRNA}$, respectively, into the MII oocytes at $40 \mathrm{~h}$ of IVM at $2 \mathrm{~h}$ before IVF. Successful injection of the antibody was verified using immunofluorescence analysis (Fig. 3 $A, A^{\prime}, B$ and $B^{\prime}$ ). The antibody specifically recognized PDIA3 in porcine oocytes, as confirmed via western blotting (Fig. 3D). Efficient inhibition or overexpression of PDIA3 in oocytes was further established from western blotting data (Fig. 3E). Based on refringency and size of the sperm nucleus, sperm were categorized as condensed (Supplementary Fig. 2A) or decondensed (Supplementary Fig. 2B), and the effects of PDIA3 on sperm nucleus decondensation in porcine oocytes were assessed. The rates of oocytes with decondensed sperm at $2 \mathrm{~h}$ after IVF in the non-injected control group $(65.58 \%)$ and IgG-injected oocytes $(69.36 \%)$ were significantly higher $(P<0.05)$ than those of anti-PDIA3injected oocytes $(40.69 \%)$ and lower $(P<0.05)$ than those of PDIA3 mRNA-injected oocytes $(84.00 \%$; Table 5). However, considering that fertilized porcine oocytes contain different amounts of sperm, the proportion of oocytes with decondensed sperm does not completely reflect the decondensation ability of oocytes. Accordingly, we assessed the decondensed sperm rate, irrespective of oocyte number. The rates of

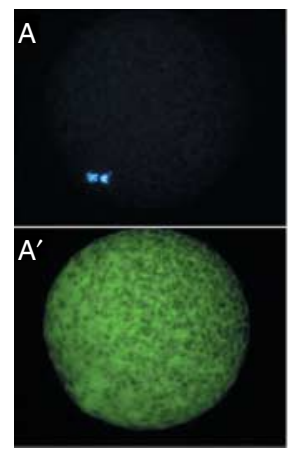

D $(\mathrm{kDa})$

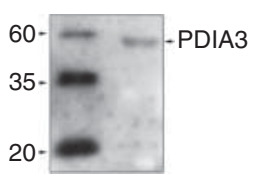

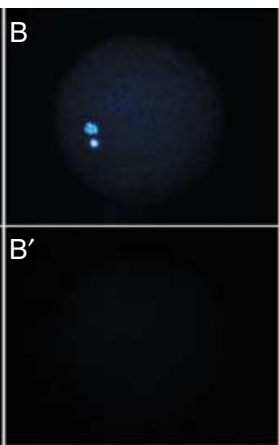

E

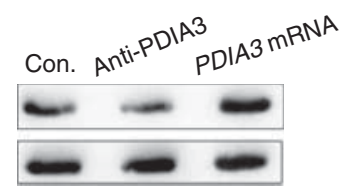

Figure 3 Efficient inhibition and overexpression of PDIA3 in oocytes. (A and $A^{\prime}$ ) Immunofluorescence analysis of anti-PDIA3 antibodyinjected oocytes without the PDIA3 primary antibody. (B and $\mathrm{B}^{\prime}$ ) Immunofluorescence analysis of oocytes without the PDIA3 primary antibody. (C and $C^{\prime}$ ) Immunofluorescence analysis of oocytes $2 \mathrm{~h}$ after anti-PDIA3 antibody injection without the PDIA3 primary antibody. (D) Specificity of the anti-PDIA3 antibody to porcine PDIA3 was verified via western blotting. (E) Inhibition of PDIA3 via antibody injection and PDIA3 overexpression with mRNA injection confirmed using western blotting. Green, anti-PDIA3 antibody; blue, DNA; bar, $50 \mu \mathrm{m}$. 
Table 5 The effect of PDIA3 on the rate of oocytes with decondensed sperms after $2 \mathrm{~h}$ of IVF.

\begin{tabular}{lccc}
\hline Groups & Replicates & $\begin{array}{c}\text { No. of } \\
\text { oocytes } \\
\text { fertilized }\end{array}$ & $\begin{array}{c}\text { No. of zygotes with } \\
\text { decondensed sperms } \\
(\% \pm \text { s.E.M. })\end{array}$ \\
\hline $\begin{array}{c}\text { Control (noninjected) } \\
\text { IgG-injected embryos }\end{array}$ & 6 & 81 & $54(65.58 \pm 8.17)^{*}$ \\
$\begin{array}{c}\text { Anti-PDIA3-injected } \\
\text { embryos }\end{array}$ & 6 & 135 & $90(69.36 \pm 9.27)^{*}$ \\
$\begin{array}{c}P D I A 3 \text { mRNA- } \\
\text { injected embryos }\end{array}$ & 6 & 167 & $69(40.69 \pm 11.12)^{+}$ \\
\hline
\end{tabular}

Values in the same column with different superscript symbols differ significantly $(P<0.05)$.

sperm decondensation in non-injected control (56.16\%) and IgG-injected oocytes (52.9\%) were significantly higher than that of anti-PDIA3-injected oocytes (28.65\%) and lower than that of PDIA3 mRNA-injected oocytes after 2 h of IVF (73.7\%; Table 6), consistent with the rates of oocytes with decondensed sperm. In addition, detection via immunostaining of the antiPDIA3 antibody in injected oocytes at $2 \mathrm{~h}$ post-injection revealed no signal, indicating that the injected antibody was degraded and had no effect on sperm-derived PDIA3 (Fig. 3C and $C^{\prime}$ ). Our results suggest that maternal PDIA3 is indispensible for successful decondensation of the sperm nucleus.

\section{PDIA3 promotes sperm decondensation by reducing protamine disulfide bonds}

PDIA3 is a multifunctional thiol-disulfide oxidoreductase that efficiently catalyzes disulfide reduction, disulfide isomerization, and dithiol oxidation in substrate proteins (Frickel et al. 2004). Therefore, we further determined whether PDIA3 plays a role in reduction of protamine disulfide bonds, the first step of sperm decondensation. Several previous studies have identified DTT as a chemical that reduces protamine disulfide bonds to promote sperm decondensation in vitro (Perreault et al. 1984, Rho et al. 1998, Nakai et al. 2006). Herein, we performed ICSI with DTT-treated and untreated sperm into IgG-injected, anti-PDIA3-injected and PDIA3 mRNA-injected oocytes (Fig. 4), and assessed the sperm decondensation rate at $3 \mathrm{~h}$ post injection. Consistent with previous findings (Perreault et al. 1984), the decondensation rate of DTT-treated sperm $(45.56 \%)$ was significantly higher $(P<0.05)$ than that of untreated sperm $(35.98 \%)$ in the IgG injection control group. In addition, in antiPDIA3-injected oocytes, decondensation of DTT-treated sperm $(41.95 \%)$ was significantly higher $(P<0.05)$ than that of untreated sperm $(11.27 \%)$. In contrast, we observed no significant differences in decondensation rates between DTT-treated $(53.97 \%)$ and untreated (56.01\%) sperm in PDIA3 mRNA-injected embryos. These findings support our hypothesis that anti-PDIA3- injected oocytes do not normally decondense the sperm nucleus, at least partly because they are unable to reduce sufficient sperm nuclear disulfide bonds.

\section{Discussion}

Generally, mature porcine oocytes collected at $42 \mathrm{~h}$ of IVM are used for IVF. In this study, we found that 330 exhibits higher competence to sustain IVF embryo development and sperm nucleus decondensation than $42 \mathrm{O}$. In view of these differences, porcine $33 \mathrm{O}$ and $42 \mathrm{O}$ provide a good model for the analysis of maternal factors responsible for fertilization and sperm decondensation. Failure of pronucleus formation (especially, male pronuclei) is one of the major reasons of infertility in clinical ART (Sousa \& Tesarik 1994, Flaherty et al. 1995, Wall et al. 1996, Rawe et al. 2000, Lee et al. 2003). Sperm nucleus decondensation is an integral step in fertilization leading to the formation of male pronuclei, therefore sperm DNA is compacted and transcriptionally inactive (Ward 2010). Disulfide bond reduction in protamines is the first step in the process of sperm nucleus decondensation (Seligman et al. 1994). The oocyte factors, known as sperm decondensation factors (SDFs), have been shown to induce this process (Moor \& Gandolfi 1987, Miyara et al. 2003). Several SDFs in oocytes that facilitate protamine removal, chromatin decondensation, and histone replacement have been identified to date (Romanato et al. 2003, 2005, 2008, Inoue et al. 2011, Julianelli et al. 2012, Yadav et al. 2013). It is suggested that SDFs are induced after GV breakdown in most mammals (Dozortsev et al. 1995), but their roles and mechanisms of action in the oocyte cytoplasm are obscure at present. In the current study, porcine oocytes with different rates of fertilization and sperm decondensation provided an effective model for further clarification of these factors.

Among the 18 differentially expressed proteins in $33 \mathrm{O}$ and $42 \mathrm{O}$ revealed by proteomic analysis, 13 have been reported previously (Ellederova et al. 2004, Novak et al. 2004, Jiang et al. 2011, Miyamoto et al. 2011). Recently, two proteins, PARK7 and VIM, have been identified as reprograming factors (Miyamoto et al. 2011,

Table 6 The effect of PDIA3 on the rate of decondensed sperms after $2 \mathrm{~h}$ of IVF.

\begin{tabular}{lccc}
\hline Groups & Replicates & $\begin{array}{c}\text { No. of sperms } \\
\text { fertilized }\end{array}$ & $\begin{array}{c}\text { No. of decondensed } \\
\text { sperms }(\% \pm \text { S.E.M.) }\end{array}$ \\
\hline $\begin{array}{l}\text { Control } \\
\text { (noninjected) }\end{array}$ & 6 & 136 & $77(56.16 \pm 5.35)^{*}$ \\
$\begin{array}{c}\text { IgG-injected } \\
\text { embryos }\end{array}$ & 6 & 263 & $172(52.9 \pm 9.50)^{*}$ \\
$\begin{array}{c}\text { Anti-PDIA3- } \\
\text { injected embryos }\end{array}$ & 6 & 220 & $171(28.65 \pm 14.05)^{+}$ \\
$\begin{array}{c}\text { PDIA3 mRNA- } \\
\text { injected embryos }\end{array}$ & 6 & 535 & $308(73.7 \pm 5.81)^{\ddagger}$ \\
\hline
\end{tabular}

Values in the same column with different superscript symbols differ significantly $(P<0.05)$. 


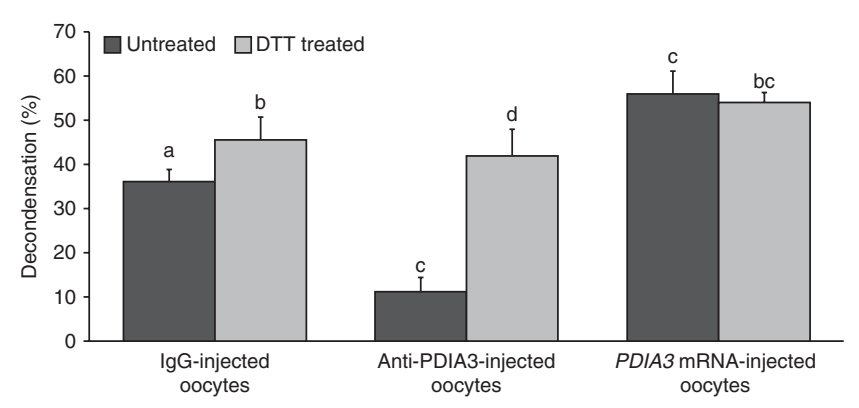

Figure 4 Percentage of decondensed sperm nucleus in PDIA3-inhibited or overexpressed oocytes injected with DTT-treated or untreated sperm. Results are presented as mean values \pm S.E.M. Different letters indicate significant differences $(P<0.05)$.

Kong et al. 2014), and PADI6 was shown to be required for early embryo development (Esposito et al. 2007). Our IVF data showing that the sperm decondensation rate in $33 \mathrm{O}$ is higher than that in $42 \mathrm{O}$ indicate that specific factors in oocytes are responsible for sperm nucleus decondensation, which differ in quantity between the $33 \mathrm{O}$ and $42 \mathrm{O}$ stages. Therefore, we focused on the proteins specifically and abundantly expressed in $33 \mathrm{O}$ and selected PDIA3 for further investigation of its potential function in sperm nuclear decondensation.

PDIA3 has been characterized and its expression confirmed in sperm, but no reports are currently available on its expression and function in oocytes. PDIA3, a $58 \mathrm{kDa}$ thiol oxidoreductase, is a member of the PDI-like family (Turano et al. 2002). The protein catalyzes disulfide bond formation, reduction or isomerization, similar to PDIs (Zapun et al. 1998, Frickel et al. 2004). PDIA3-deficient mice are embryonically lethal at stage 13.5 post-coitum, indicating a critical role in embryonic development (Coe et al. 2010). PDIA3 is located in the developing acrosome of spermatids during rat spermatogenesis and on the adult mouse sperm membrane. A role of PDIA3 in gamete fusion has been reported (Ellerman et al. 2006, Zhang et al. 2007). However, no information regarding the function of maternal PDIA3 has been documented. Our experiments showed that large amounts of PDIA3 accumulate in oocytes. Inhibition of maternal PDIA3 resulted in sperm decondensation failure, while its overexpression in oocytes promoted sperm decondensation in porcine IVF and ICSI zygotes. In addition, we did not detect a signal of sperm-derived PDIA3 in ICSI embryos (Supplementary Fig. 3, see section on supplementary data given at the end of this article), indicating that the influence of sperm-derived PDIA3 can be excluded. Our data collectively imply a crucial role of PDIA3 in sperm nucleus decondensation.

Decondensation of the sperm nucleus starts with reduction of disulfide bonds in protamine, following which other SDFs gain access to the sperm nucleus and facilitate chromatin dispersal and removal of protamine from DNA (Perreault et al. 1984, 1987, Ward 2010).
In our study, failure of sperm decondensation in PDIA3deficient oocytes was rescued by DTT, a commonly used disulfide bond-reducing reagent that facilitates sperm decondensation in bovine and porcine ICSI embryos (Rho et al. 1998, Nakai et al. 2006), indicating that maternal PDIA3 reduces protamine disulfide bonds to promote sperm decondensation. Accordingly, we propose that maternal PDIA3 promotes sperm decondensation by reducing protamine disulfide bonds, similar to the mechanism of glutathione activity in sperm decondensation in oocytes (Perreault et al. 1988).

In summary, we found that matured porcine oocytes collected at 33 and $42 \mathrm{~h}$ have different capabilities to promote fertilization and embryonic development. We further identified and characterized 18 differentially expressed proteins via proteomic analysis, among which one oocyte factor, PDIA3, was characterized as a SDF that acts through reduction of protamine disulfide bonds. The results from this study support the utility of PDIA3 as a potential factor for oocyte selection in assisted reproduction techniques in the clinic.

\section{Supplementary data}

This is linked to the online version of the paper at http://dx.doi. org/10.1530/REP-14-0264.

\section{Declaration of interest}

The authors declare that there is no conflict of interest that could be perceived as prejudicing the impartiality of the research reported.

\section{Funding}

This work was support by the National Natural Science Foundation of China (grant number, 31371457) and the National Basic Research Program of China (973 Program) (grant number, 2011CB944202).

\section{References}

Brevini TA, Cillo F, Antonini S, Tosetti V \& Gandolfi F 2007a Temporal and spatial control of gene expression in early embryos of farm animals. Reproduction, Fertility, and Development 19 35-42. (doi:10.1071/ RD06119)

Brevini TA, Antonini S, Cillo F, Crestan M \& Gandolfi F 2007b Porcine embryonic stem cells: facts, challenges and hopes. Theriogenology 68 (Suppl 1) S206-S213. (doi:10.1016/j.theriogenology.2007.05.043)

Burns KH, Viveiros MM, Ren Y, Wang P, DeMayo FJ, Frail DE, Eppig JJ \& Matzuk MM 2003 Roles of NPM2 in chromatin and nucleolar organization in oocytes and embryos. Science 300 633-636. (doi:10. 1126/science.1081813)

Calvert ME, Digilio LC, Herr JC \& Coonrod SA 2003 Oolemmal proteomics - identification of highly abundant heat shock proteins and molecular chaperones in the mature mouse egg and their localization on the plasma membrane. Reproductive Biology and Endocrinology 1 27. (doi:10. 1186/1477-7827-1-27) 
Coe H, Jung J, Groenendyk J, Prins D \& Michalak M 2010 ERp57 modulates STAT3 signaling from the lumen of the endoplasmic reticulum. Journal of Biological Chemistry 285 6725-6738. (doi:10.1074/jbc.M109.054015)

Dozortsev D, De Sutter P, Rybouchkin A \& Dhont M 1995 Timing of sperm and oocyte nuclear progression after intracytoplasmic sperm injection. Human Reproduction 10 3012-3017.

Ellederova Z, Halada P, Man P, Kubelka M, Motlik J \& Kovarova H 2004 Protein patterns of pig oocytes during in vitro maturation. Biology of Reproduction 71 1533-1539. (doi:10.1095/biolreprod.104.030304)

Ellerman DA, Myles DG \& Primakoff PA 2006 A role for sperm surface protein disulfide isomerase activity in gamete fusion: evidence for the participation of ERp57. Developmental Cell 10 831-837. (doi:10.1016/ j.devcel.2006.03.011)

Esposito G, Vitale AM, Leijten FP, Strik AM, Koonen-Reemst AM, Yurttas P, Robben TJ, Coonrod S \& Gossen JA 2007 Peptidylarginine deiminase (PAD) 6 is essential for oocyte cytoskeletal sheet formation and female fertility. Molecular and Cellular Endocrinology 273 25-31. (doi:10.1016/ j.mce.2007.05.005)

Flaherty SP, Payne D, Swann NJ \& Mattews CD 1995 Aetiology of failed and abnormal fertilization after intracytoplasmic sperm injection. Human Reproduction 10 2623-2629.

Frickel EM, Frei P, Bouvier M, Stafford WF, Helenius A, Glockshuber R \& Ellgaard L 2004 ERp57 is a multifunctional thiol-disulfide oxidoreductase. Journal of Biological Chemistry 279 18277-18287. (doi:10. 1074/jbc.M314089200)

Funahashi H \& Day BN 1997 Advances in in vitro production of pig embryos. Journal of Reproduction and Fertility. Supplement 52 271-283.

Gosden RG 2002 Oogenesis as a foundation for embryogenesis. Molecular and Cellular Endocrinology 186 149-153. (doi:10.1016/S03037207(01)00683-9)

Hall V 2008 Porcine embryonic stem cells: a possible source for cell replacement therapy. Stem Cell Reviews 4 275-282. (doi:10.1007/ s12015-008-9040-2)

Hamatani T, Carter MG, Sharov AA \& Ko MS 2004 Dynamics of global gene expression changes during mouse preimplantation development. Developmental Cell 6 117-131. (doi:10.1016/S1534-5807(03)00373-3)

He W, Kong Q, Shi Y, Xie B, Jiao M, Huang T, Guo S, Hu K \& Liu Z 2013 Generation and developmental characteristics of porcine tetraploid embryos and tetraploid/diploid chimeric embryos. Genomics, Proteomics \& Bioinformatics 11 327-333. (doi:10.1016/j.gpb.2013.09.007)

Inoue A, Ogushi S, Saitou M, Suzuki MG \& Aoki F 2011 Involvement of mouse nucleoplasmin 2 in the decondensation of sperm chromatin after fertilization. Biology of Reproduction 85 70-77. (doi:10.1095/biolreprod.110.089342)

Jiang GJ, Wang K, Miao DQ, Guo L, Hou Y, Schatten H \& Sun QY 2011 Protein profile changes during porcine oocyte aging and effects of caffeine on protein expression patterns. PLOS ONE 6 e28996. (doi:10. 1371/journal.pone.0028996)

Julianelli V, Farrando B, Alvarez Sedo C, Calvo L, Romanato M \& Calvo JC 2012 Heparin enhances protamine disulfide bond reduction during in vitro decondensation of human spermatozoa. Human Reproduction 27 1930-1938. (doi:10.1093/humrep/des139)

Katz P, Nachtigall R \& Showstack J 2002 The economic impact of the assisted reproductive technologies. Nature Cell Biology 4 (Suppl) s29-s32. (doi:10.1038/ncb-nm-fertilityS29)

Kong Q, Xie B, Li J, Huan Y, Huang T, Wei R, Lv J, Liu S \& Liu Z 2014 Identification and characterization of an oocyte factor required for porcine nuclear reprogramming. Journal of Biological Chemistry 289 6960-6968. (doi:10.1074/jbc.M113.543793)

Krisher RL 2004 The effect of oocyte quality on development. Journal of Animal Science 82 E14-E23.

Lee JW, Tian XC \& Yang X 2003 Failure of male pronucleus formation is the major cause of lack of fertilization and embryo development in pig oocytes subjected to intracytoplasmic sperm injection. Biology of Reproduction 68 1341-1347. (doi:10.1095/biolreprod.102.009001)

Li L, Baibakov B \& Dean J 2008 A subcortical maternal complex essential for preimplantation mouse embryogenesis. Developmental Cell $\mathbf{1 5}$ 416-425. (doi:10.1016/j.devcel.2008.07.010)

Mahutte NG \& Arici A 2003 Failed fertilization: is it predictable? Current Opinion in Obstetrics \& Gynecology 15 211-218. (doi:10.1097/ 00001703-200306000-00001)
Memili E, Peddinti D, Shack LA, Nanduri B, McCarthy F, Sagirkaya H \& Burgess SC 2007 Bovine germinal vesicle oocyte and cumulus cell proteomics. Reproduction 133 1107-1120. (doi:10.1530/REP-06-0149)

Miyamoto K, Nagai K, Kitamura N, Nishikawa T, Ikegami H, Binh NT, Tsukamoto S, Matsumoto M, Tsukiyama T, Minami N et al. 2011 Identification and characterization of an oocyte factor required for development of porcine nuclear transfer embryos. PNAS $\mathbf{1 0 8}$ 7040-7045. (doi:10.1073/pnas.1013634108)

Miyara F, Aubriot FX, Glissant A, Nathan C, Douard S, Stanovici A, Herve F, Dumont-Hassan M, LeMeur A, Cohen-Bacrie P et al. 2003 Multiparameter analysis of human oocytes at metaphase II stage after IVF failure in non-male infertility. Human Reproduction 18 1494-1503. (doi:10.1093/humrep/deg272)

Moor RM \& Gandolfi F 1987 Molecular and cellular changes associated with maturation and early development of sheep eggs. Journal of Reproduction and Fertility. Supplement 34 55-69.

Morisato D \& Anderson KV 1995 Signaling pathways that establish the dorsal-ventral pattern of the Drosophila embryo. Annual Review of Genetics 29 371-399. (doi:10.1146/annurev.genet.29.1.371)

de Mouzon J, Goossens V, Bhattacharya S, Castilla JA, Ferraretti AP, Korsak V, Kupka M, Nygren KG \& Nyboe Andersen A 2010 Assisted reproductive technology in Europe, 2006: results generated from European registers by ESHRE. Human Reproduction 25 1851-1862. (doi:10.1093/humrep/deq124)

Nakai M, Kashiwazaki N, Takizawa A, Maedomari N, Ozawa M, Noguchi J, Kaneko H, Shino M \& Kikuchi K 2006 Morphologic changes in boar sperm nuclei with reduced disulfide bonds in electrostimulated porcine oocytes. Reproduction 131 603-611. (doi:10.1530/rep.1.01001)

Newport J \& Kirschner M 1982 A major developmental transition in early Xenopus embryos: II. Control of the onset of transcription. Cell 30 687-696. (doi:10.1016/0092-8674(82)90273-2)

Novak S, Paradis F, Savard C, Tremblay K \& Sirard MA 2004 Identification of porcine oocyte proteins that are associated with somatic cell nuclei after co-incubation. Biology of Reproduction 71 1279-1289. (doi:10.1095/ biolreprod.103.027037)

Payer B, Saitou M, Barton SC, Thresher R, Dixon JP, Zahn D, Colledge WH, Carlton MB, Nakano T \& Surani MA 2003 Stella is a maternal effect gene required for normal early development in mice. Current Biology $\mathbf{1 3}$ 2110-2117. (doi:10.1016/j.cub.2003.11.026)

Perreault SD, Wolff RA \& Zirkin BR 1984 The role of disulfide bond reduction during mammalian sperm nuclear decondensation in vivo. Developmental Biology 101 160-167. (doi:10.1016/0012-1606(84) 90126-X)

Perreault SD, Naish SJ \& Zirkin BR 1987 The timing of hamster sperm nuclear decondensation and male pronucleus formation is related to sperm nuclear disulfide bond content. Biology of Reproduction 36 239-244. (doi:10.1095/biolreprod36.1.239)

Perreault SD, Barbee RR \& Slott VL 1988 Importance of glutathione in the acquisition and maintenance of sperm nuclear decondensing activity in maturing hamster oocytes. Developmental Biology 125 181-186. (doi:10.1016/0012-1606(88)90070-X)

Rawe VY, Olmedo SB, Nodar FN, Doncel GD, Acosta AA \& Vitullo AD 2000 Cytoskeletal organization defects and abortive activation in human oocytes after IVF and ICSI failure. Molecular Human Reproduction 6 510-516. (doi:10.1093/molehr/6.6.510)

Rho GJ, Kawarsky S, Johnson WH, Kochhar K \& Betteridge KJ 1998 Sperm and oocyte treatments to improve the formation of male and female pronuclei and subsequent development following intracytoplasmic sperm injection into bovine oocytes. Biology of Reproduction $\mathbf{5 9}$ 918-924. (doi:10.1095/biolreprod59.4.918)

Romanato M, Cameo MS, Bertolesi G, Baldini C, Calvo JC \& Calvo L 2003 Heparan sulphate: a putative decondensing agent for human spermatozoa in vivo. Human Reproduction 18 1868-1873. (doi:10.1093/humrep/ $\operatorname{deg} 354)$

Romanato M, Regueira E, Cameo MS, Baldini C, Calvo L \& Calvo JC 2005 Further evidence on the role of heparan sulfate as protamine acceptor during the decondensation of human spermatozoa. Human Reproduction 20 2784-2789. (doi:10.1093/humrep/dei124)

Romanato M, Julianelli V, Zappi M, Calvo L \& Calvo JC 2008 The presence of heparan sulfate in the mammalian oocyte provides a clue to human sperm nuclear decondensation in vivo. Human Reproduction 23 1145-1150. (doi:10.1093/humrep/den028) 
Seligman J, Kosower NS, Weissenberg R \& Shalgi R 1994 Thiol-disulfide status of human sperm proteins. Journal of Reproduction and Fertility 101 435-443. (doi:10.1530/jrf.0.1010435)

Society for Assisted Reproductive Technology; American Society for Reproductive Medicine 2004 Assisted reproductive technology in the United States: 2000 results generated from the American Society for Reproductive Medicine/Society for Assisted Reproductive Technology Registry. Fertility and Sterility 81 1207-1220. (doi:10.1016/j.fertnstert. 2004.01.017)

Sousa M \& Tesarik J 1994 Ultrastructural analysis of fertilization failure after intracytoplasmic sperm injection. Human Reproduction 9 2374-2380.

Sternlicht AL \& Schultz RM 1981 Biochemical studies of mammalian oogenesis: kinetics of accumulation of total and poly(A)-containing RNA during growth of the mouse oocyte. Journal of Experimental Zoology 215 191-200. (doi:10.1002/jez.1402150209)

Sun QY \& Nagai T 2003 Molecular mechanisms underlying pig oocyte maturation and fertilization. Journal of Reproduction and Development 49 347-359. (doi:10.1262/jrd.49.347)

Susor A, Ellederova Z, Jelinkova L, Halada P, Kavan D, Kubelka M \& Kovarova H 2007 Proteomic analysis of porcine oocytes during in vitro maturation reveals essential role for the ubiquitin C-terminal hydrolaseL1. Reproduction 134 559-568. (doi:10.1530/REP-07-0079)

Swain JE \& Pool TB 2008 ART failure: oocyte contributions to unsuccessful fertilization. Human Reproduction Update 14 431-446. (doi:10.1093/ humupd/dmn025)

Tong ZB, Gold L, Pfeifer KE, Dorward H, Lee E, Bondy CA, Dean J \& Nelson LM 2000 Mater, a maternal effect gene required for early embryonic development in mice. Nature Genetics 26 267-268. (doi:10. 1038/81547)

Turano C, Coppari S, Altieri F \& Ferraro A 2002 Proteins of the PDI family: unpredicted non-ER locations and functions. Journal of Cellular Physiology 193 154-163. (doi:10.1002/jcp.10172)

Vitale AM, Calvert ME, Mallavarapu M, Yurttas P, Perlin J, Herr J \& Coonrod S 2007 Proteomic profiling of murine oocyte maturation. Molecular Reproduction and Development 74 608-616. (doi:10.1002/ mrd.20648)

Wall MB, Marks K, Smith TA, Gearon CM \& Muggleton-Harris AL 1996 Cytogenetic and fluorescent in-situ hybridization chromosomal studies on in-vitro fertilized and intracytoplasmic sperm injected 'failedfertilized' human oocytes. Human Reproduction $112230-2238$. (doi:10.1093/oxfordjournals.humrep.a019082)

Wang QT, Piotrowska K, Ciemerych MA, Milenkovic L, Scott MP, Davis RW \& Zernicka-Goetz M 2004 A genome-wide study of gene activity reveals developmental signaling pathways in the preimplantation mouse embryo. Developmental Cell 6 133-144. (doi:10.1016/S15345807(03)00404-0)

Wang S, Kou Z, Jing Z, Zhang Y, Guo X, Dong M, Wilmut I \& Gao S 2010 Proteome of mouse oocytes at different developmental stages. PNAS $\mathbf{1 0 7}$ 17639-17644. (doi:10.1073/pnas.1013185107)

Ward WS 2010 Function of sperm chromatin structural elements in fertilization and development. Molecular Human Reproduction 16 30-36. (doi:10.1093/molehr/gap080)

Yadav VK, Saraswat M, Chhikara N, Singh S \& Yadav S 2013 Heparin and heparin binding proteins: potential relevance to reproductive physiology. Current Protein \& Peptide Science 14 61-69. (doi:10.2174/ 1389203711314010009)

Zapun A, Darby NJ, Tessier DC, Michalak M, Bergeron JJ \& Thomas DY 1998 Enhanced catalysis of ribonuclease B folding by the interaction of calnexin or calreticulin with ERp57. Journal of Biological Chemistry 273 6009-6012. (doi:10.1074/jbc.273.11.6009)

Zeng F, Baldwin DA \& Schultz RM 2004 Transcript profiling during preimplantation mouse development. Developmental Biology 272 483-496. (doi:10.1016/j.ydbio.2004.05.018)

Zhang J, Wu J, Huo R, Mao Y, Lu Y, Guo X, Liu J, Zhou Z, Huang X \& Sha J 2007 ERp57 is a potential biomarker for human fertilization capability. Molecular Human Reproduction 13 633-639. (doi:10.1093/molehr/ gam049)

Zhang P, Ni X, Guo Y, Guo X, Wang Y, Zhou Z, Huo R \& Sha J 2009 Proteomic-based identification of maternal proteins in mature mouse oocytes. BMC Genomics 10 348. (doi:10.1186/1471-2164-10-348)

Received 24 May 2014

First decision 11 June 2014

Revised manuscript received 4 July 2014

Accepted 15 July 2014 